\title{
UK validation of the Tinnitus Functional Index (TFI) in a large research population
}

\author{
Kathryn Fackrell ${ }^{1 *}$, Deborah A Hall', Johanna G Barry², Derek J Hoare ${ }^{1}$ \\ From The 4th Meeting of the Core Outcome Measures in Effectiveness Trials (COMET) Initiative \\ Rome, Italy. 19-20 November 2014
}

\section{Background}

Questionnaires are essential for measurement of tinnitus severity and treatment-related change. Yet no standard measure is used across clinical and research settings. Current tinnitus questionnaires are limited to measuring severity or change, but not both $[1,2]$. The Tinnitus Functional Index (TFI) was developed as both a diagnostic measure of the functional impact of tinnitus and to be a sensitive measure of treatment-related change [3]. It has not, however, been fully validated. This present study evaluates the validity of the TFI as a diagnostic measure of tinnitus severity in a UK research population.

\section{Methods}

The study involved a retrospective analysis of data collected for 294 participants who had previously participated in a randomised controlled trial of a novel tinnitus device [4]. Participants completed a series of questionnaires including the TFI, Tinnitus Handicap Inventory (THI) [5], Tinnitus Handicap Questionnaire (THQ) [6], a Visual Analogue Scale of Loudness (VASL) [7], a Percentage Rating of Annoyance (PR-A), Beck's Depression Inventory (BDI) [8], Beck's Anxiety Inventory (BAI) [9], and the World Health Organisation Quality of Life Bref (WHOQOL) [10]. Forty four participants, who completed the TFI at a second visit (within 21 days), provided data for reliability assessment. Psychometric analyses included (1) Confirmatory factor analysis (CFA) using the current eight subscales proposed for the TFI development; (2) Convergent and discriminant validity; and (3) Test-retest reliability and agreement.

\footnotetext{
* Correspondence: msxklf@nottingham.ac.uk

'NIHR Nottingham Hearing Biomedical Research Unit, Division of Clinical Neuroscience, School of Medicine, University of Nottingham, Nottingham, NG1 5DU, UK

Full list of author information is available at the end of the article
}

\section{Results}

The TFI structure showed acceptable model fit (RMSEA = 0.65 ), although it was not optimal. The auditory factor in particular was unrelated to the other factors and the underlying construct of "the functional impact of tinnitus on daily life". Acceptable convergent and discriminant validity was demonstrated by the high correlations between the scores on the TFI and THI $(r=0.82)$ and THQ $(r=0.82)$, moderate correlations with VAS-L $(r=$ $0.46)$, PR-A $(r=0.58)$, BDI $(r=0.57)$, BAI $(r=0.38)$ and WHOQOL $(r=-0.48)$. Reliability assessments indicated high test-retest reliability for the TFI global scores (ICC $=$ 0.86 ) and borderline acceptable test-retest agreement for the TFI global scores (93\%).

\section{Conclusion}

The TFI does cover multiple symptom domains and provides a valid measure of tinnitus that can reliably distinguish between individuals in this population. The proposed 8-factor structure, however, was not fully confirmed. Given these results, it may be more appropriate to view each subscale individually rather the combining the subscales to create a global score. Further investigation of the TFI structure and sensitivity to treatmentrelated change is warranted.

\footnotetext{
Authors' details

${ }^{1}$ NIHR Nottingham Hearing Biomedical Research Unit, Division of Clinical Neuroscience, School of Medicine, University of Nottingham, Nottingham, NG1 5DU, UK. ${ }^{2} \mathrm{MRC}$ Institute of Hearing Research Clinical Section, Queens Medical Centre, Nottingham, NG7 2UH, UK.
}

Published: 29 May 2015

\section{References}

1. Fackrell K, Hall DA, Barry JG, Hoare DJ: Tools for tinnitus measurement: Development and validity of questionnaires to assess handicap and treatment effects. In Tinnitus: Causes, Treatment and Short \& Long-Term Health Effects. New York: Nova Science Publishers Inc;Signorelli F \& Turjman F 2014:13-60. 
2. Newman CW, Sandridge SA: Tinnitus Questionnaires. In Tinnitus: Theory and Management. Ontario: BC Decker Inc;Snow Jr JB 2004:237-254.

3. Meikle MB, Henry JA, Griest SE, Stewart BJ, Abrams HB, Vernon JA, et al: The Tinnitus Functional Index: Development of a New Clinical Measure for Chronic, Intrusive Tinnitus. Ear Hear 2012, 33:153-176.

4. Hoare DJ, Pierzycki RH, Thomas H, McAlpine D, Hall DA: Evaluation of the acoustic coordinated reset $\left(\mathrm{CR}^{\oplus}\right)$ neuromodulation therapy for tinnitus: study protocol for a double-blind randomized placebo-controlled trial. Trials 2013, 14:207.

5. Newman CW, Jacobson GP, Spitzer JB: Development of the tinnitus handicap inventory. Otolaryngol Head Neck Surg 1996, 122:143-148.

6. Kuk FK, Tyler RS, Russell D, Jordan H: The Psychometric Properties of a Tinnitus Handicap Questionnaire. Ear Hear 1990, 11:434-445.

7. Borg G, Borg E: A new generation of scaling methods: level anchored ratio scaling. Psychologica 2001, 28:15-45.

8. Beck AT, Steer RA, Brown GK: Manual for the Beck Depression Inventory -II. San Antonio, TX: Psychological Corporation; 21996.

9. Beck AT, Steer RA: Manual for the Beck Anxiety Inventory. San Antonio, TX: The Psychological Corporation; 1990.

10. The WHOQOL Group: Development of the World Health Organization WHOQOL-BREF quality of life assessment. Psychol. Med 1998, 28:551-558.

doi:10.1186/1745-6215-16-S1-P20

Cite this article as: Fackrell et al:: UK validation of the Tinnitus

Functional Index (TFI) in a large research population. Trials 2015

16(Suppl 1):P20.

\section{Submit your next manuscript to BioMed Central} and take full advantage of:

- Convenient online submission

- Thorough peer review

- No space constraints or color figure charges

- Immediate publication on acceptance

- Inclusion in PubMed, CAS, Scopus and Google Scholar

- Research which is freely available for redistribution

Submit your manuscript at www.biomedcentral.com/submit 